\title{
Host Specificity and Spatial Distribution Preference of Three Pseudomonas Isolates
}

\author{
Nesli Tovi ${ }^{1,2}$, Sammy Frenk ${ }^{3}$, Yitzhak Hadar ${ }^{2}$ and Dror Minz ${ }^{1 *}$ \\ ${ }^{1}$ Department of Soil, Water, and Environmental Sciences, Agricultural Research Organization-Volcani Center, Rishon LeZion, \\ Israel, ${ }^{2}$ Department of Plant Pathology and Microbiology, Robert H. Smith Faculty of Agriculture, Food and Environment, \\ The Hebrew University of Jerusalem, Rehovot, Israel, ${ }^{3}$ Australian Centre for Ecogenomics, School of Chemistry and \\ Molecular Biosciences, The University of Queensland, St Lucia, QLD, Australia
}

\section{OPEN ACCESS}

Edited by:

Jesús Mercado-Blanco,

Spanish National Research Council

(CSIC), Spain

Reviewed by:

Carmen Bianco,

Italian National Research Council, Italy

Nicolas Ayub,

Consejo Nacional de Investigaciones Cientificas y Técnicas (CONICET),

Argentina

${ }^{*}$ Correspondence:

Dror Minz

minz@volcani.agri.gov.il

Specialty section:

This article was submitted to Plant Microbe Interactions,

a section of the journal

Frontiers in Microbiology

Received: 18 October 2018 Accepted: 14 December 2018

Published: 10 January 2019

Citation:

Tovi N, Frenk S, Hadar Y and Minz D (2019) Host Specificity and Spatial Distribution Preference of Three

Pseudomonas Isolates.

Front. Microbiol. 9:3263.

doi: 10.3389/fmicb.2018.03263
Plant hosts recruit and maintain a distinct root-associated microbiota based on host and bacterium traits. However, past studies disregarded microbial strain-host specificity and spatial micro-heterogeneity of the root compartment. Using genetic manipulation, confocal laser scanning microscopy, real-time quantitative PCR, and genome sequencing we characterized the colonization patterns of three Pseudomonas spp. isolates native to wheat roots, on the micro-scale. Namely, isolates $P$. fluorescens NT0133, P. stutzeri NT124, and P. stutzeri NT128. All three isolates preferentially colonized wheat over cucumber roots that served as control for host specificity. Furthermore, not only had the isolates strong host specificity but each isolate had a distinct spatial distribution on the root, all within a few millimeters. Isolate P. stutzeri-NT0124 preferentially colonized root tips, whereas P. fluorescens-NT0133 showed a preference for zones distant from the tip. In contrast, isolate $P$. stutzeri-NT0128 had no preference for a specific niche on the root. While all isolates maintained genetic potential for motility and biofilm formation their phenotype varied significantly and corresponded to their niche preference. These results demonstrate the importance of spatial colonization patterns, governed by both niche and bacterial characteristics which will have great importance in future attempts to manipulate the plant microbiome by constructing synthetic microbial consortia.

Keywords: isolates, roots, distribution, niche, host, Pseudomonas, colonization

\section{INTRODUCTION}

The microbiome of plant roots was shown to have profound effects on growth, nutrition, and health of their plant host. While microbial abundance and diversity in soil are enormous, only specific microbial populations colonize the roots. Root communities are typically less diverse, but of higher abundance than in bulk soil (Uroz et al., 2010; Philippot et al., 2013), mainly due to the contribution of root deposits. Plant type and location on the root affect composition and amount of deposits and the bacterial fraction of the microbiome it hosts (Kravchenko et al., 2003; Jones et al., 2004; Ofek-Lalzar et al., 2014). Recent developments in sequencing technologies expanded our knowledge on root bacterial communities and revealed, to some extent, how plants can influence 
the composition and activity of their colonizers (Kravchenko et al., 2003; Jones et al., 2004; Ofek-Lalzar et al., 2014; Lareen et al., 2016; Rascovan et al., 2016; Poole, 2017). Despite that, the role of plant host in determining which specific bacteria species colonize its environment is not fully understood.

Colonization was defined as the early step of plant-bacteria interaction (Rodríguez-Navarro et al., 2007; Lugtenberg and Kamilova, 2009). Several important traits offer a selective advantage for bacterial colonization, enabling a bacterium to attach, thrive and compete with others on this unique environment. Among these traits is motility, based mostly on chemotaxis, allowing sensing and reaching the root surface. It has been shown that non-motile or reduced motility mutants are highly impaired in competitive root colonization (Harshey, 2003). Another important bacterial trait enabling an advantage during root colonization is biofilm formation. Most bacteria are found in nature attached to surfaces in multicellular assemblies known as biofilms (Ramey et al., 2004). In the root system, bacteria that are found in biofilm state have several advantages, allowing the organisms that compete in root colonization to create themselves a better protected niche (Lugtenberg et al., 2001).

Past studies have shown that members of the genus Pseudomonas are among the most abundant bacteria in root environments of several plant species, particularly those of wheat (Velázquez-Sepúlveda et al., 2012; Ofek-Lalzar et al., 2014; Rascovan et al., 2016). Ofek et al. (2014) showed that root surface microbiomes exhibited a host specific signature effect with specific genetic composition and abundances of bacterial taxa. However, Pseudomonas abundance was scarce on cucumber and tomato roots, when grown under identical conditions (Ofek et al., 2014). The specific relationships of Pseudomonas species with their host were shown to promote host health and growth (Rainey, 1999; Lugtenberg and Kamilova, 2009; Santoyo et al., 2012). For example, some P. fluorescens strains were reported to act as biological control agents against the pathogenic fungus Gaeumannomyces graminis var. tritic, responsible for the Take-all disease in wheat (Weller, 1988, 2007; Capper and Higgins, 1993).

The occurrence of several related organisms coexisting in the same niche is a subject for many studies. Little is known about the spatial distribution patterns and preference of roots isolates. The current study seeks to assess colonization specificity of three Pseudomonas isolates in two different plant hosts- wheat and cucumber, as well as colonization patterns on the roots. To do so, we isolated several dominant Pseudomonas strains from wheat roots and showed that colonization of these Pseudomonads is indeed plant host dependent. We characterized colonization traits such as motility and biofilm formation of the isolates and used confocal laser-scanning microscopy (CLSM) together with real-time quantitative PCR (qPCR) for studying colonization localization and level.

The experiments were designed in accordance to ecological theories, such as "limiting similarity" (MacArthur and Levins, 1967), dictating the number of similar species occupying the same niche and "competitive exclusion principle" when species compete for the same resource (Gause, 1936). We hypothesized that traits such as motility and biofilm formation may indicate which isolate will be a better root colonizer. Lastly, based on previous metagenome studies, we predicted that the Pseudomonas isolates would differ in colonization of wheat roots vs. cucumber roots. Our results indeed indicate that these three related Pseudomonas isolates differ in spatial distribution on wheat roots: root tips vs. zone distant from the tip, while one isolate did not prefer a specific location.

\section{MATERIALS AND METHODS}

\section{Bacterial Stains and Media}

The bacterial strains and plasmids that were used in this study are listed in Table $\mathbf{1}$ and primers used are listed in Table 2. Bacteria were grown on Luria-Bertani broth (LB): 1\% Tryptone (Difco Laboratories, USA) $0.5 \%$ yeast Extract (Difco Laboratories, USA) and $0.5 \%$ sodium chloride (Merck, Germany).These media were also used for biofilm formation, motility, plant colonization, taxonomic classification, and for molecular methods (including: bacterial DNA extraction and plasmid purification). For the purpose of Pseudomonas spp. isolation, King's B medium was used [2\% peptone (Difco Laboratories, USA), $0.15 \%$ heptahydrated magnesium sulfate (Merck, Germany), 0.15\%, potassium hydrogen phosphate (Merck, Germany), 0.1\% glycerol (BP229-1, Fisher Scientific, USA)]. Solid media was prepared by adding $1.5 \%$ Bacto agar to LB or King's B media. Where appropriate, antibiotics were added to maintain or select for plasmids as follows: for E. coli, ampicillin (Ap, 171254, Calbiochem, USA) at $100 \mu \mathrm{g} / \mathrm{mL}$ and gentamicin (Gm, G3632, Sigma, USA) at $15 \mu \mathrm{g} / \mathrm{mL}$ and for all Pseudomonas isolates, $\mathrm{Gm}$ at $30 \mu \mathrm{g} / \mathrm{mL}$.

\section{Isolation, Identification, and Phylogenetic Analysis of Wheat Root Pseudomonas spp.}

Wheat seeds (Triticum turgidum cv. Negev) were surfacesterilized by soaking in 3\% sodium hypochlorite for $1.5 \mathrm{~min}$, followed by $70 \%$ ethanol for $1.5 \mathrm{~min}$, and three washes with water. The sterilized seeds were planted in sandy loam soil $(81 \%$ sand, $6 \%$ silt, and $13 \%$ clay) obtained from Maon region in the Negev, Israel $(31.21 \mathrm{~N} 34.27 \mathrm{E})$. The seeds were germinated and grown at $25^{\circ} \mathrm{C}$ for 12 days, until first true leaf appeared. Plants were irrigated with half-strength Hoagland solution when needed (Ofek et al., 2014). After 12 days, the plants were carefully removed and the roots were separated from the shoots and washed in sterile saline 3 times. The roots were then vortexed for $30 \mathrm{~min}$ in $10 \mathrm{ml}$ saline $(0.85 \% \mathrm{NaCl})$ to extract adhering bacteria. The roots were then removed and serial dilutions of the remaining saline was plated on King's B medium for isolation of Pseudomonas species (King et al., 1954). Strain identification as belonging to the genus Pseudomonas was confirmed by PCR using two sets of Pseudomonas specific primers listed in Table 2 (F311Ps_f, Ps-rev_r, rpoB_4042-4062_R, rpoB_3159-3178_F) and by sequencing parts of $16 \mathrm{~S}$ rRNA and $r p o B$ genes using Sanger sequencing (MCLAB, San Francisco, USA). Resulting sequences were compared to the $\mathrm{nr}$ database using online BLAST tool. Enterobacterial repetitive intergenic consensus sequences (ERIC) PCR was performed to cluster identical isolates, as described previously (De Bruijn, 1992). 
TABLE 1 | List of strains and plasmids used in this study and their source.

\begin{tabular}{|c|c|c|}
\hline Strains & $\begin{array}{l}\text { Relevant genotype or } \\
\text { sequence }\end{array}$ & $\begin{array}{l}\text { Source or } \\
\text { reference }\end{array}$ \\
\hline$P$. aeruginosa $\mathrm{PAO} 1$ & Wild type & $\begin{array}{l}\text { Holloway, } \\
1955\end{array}$ \\
\hline Pseudomonas stutzeri NT0124 & $\begin{array}{l}\text { Isolated from wheat roots- } \\
\text { PRJNA273703 }\end{array}$ & This research \\
\hline Pseudomonas stutzeri NT0128 & $\begin{array}{l}\text { Isolated from wheat roots- } \\
\text { PRJNA275697 }\end{array}$ & This research \\
\hline $\begin{array}{l}\text { Pseudomonas fluorescens } \\
\text { NT0133 }\end{array}$ & $\begin{array}{l}\text { Isolated from wheat roots- } \\
\text { PRJNA275699 }\end{array}$ & This research \\
\hline $\begin{array}{l}\text { NT0124/pBT270: } \\
\text { miniTn7T-Gm-GFP }\end{array}$ & $\begin{array}{l}\mathrm{Ap}^{r} \text { and } \mathrm{Gm}^{r} \text {, } \\
\text { pUCP18-miniTn7T2.1 -GFP }\end{array}$ & This research \\
\hline $\begin{array}{l}\text { NT0128/pBT270: } \\
\text { miniTn7T-Gm-GFP }\end{array}$ & $\begin{array}{l}\text { Ap }^{r} \text { and } G m^{r} \\
\text { pUCP18-miniTn7T2.1 -GFP }\end{array}$ & This research \\
\hline $\begin{array}{l}\text { NT0133/pBT270: } \\
\text { miniTn7T-Gm-GFP }\end{array}$ & $\begin{array}{l}\mathrm{Ap}^{r} \text { and } \mathrm{Gm}^{r} \text {, } \\
\text { pUCP18-miniTn7T2.1 -GFP }\end{array}$ & This research \\
\hline \multicolumn{3}{|l|}{ PLASMIDS } \\
\hline $\begin{array}{l}\text { pBT270/ } \\
\text { pUCP18-miniTn7T2.1Gm- GFP }\end{array}$ & $\begin{array}{l}\mathrm{Ap}^{r} \text { and } \mathrm{Gm}^{r} \text {, } \\
\text { Mini-Tn7-gfp(mut3). } \\
\text { Integration vector for gfp. }\end{array}$ & $\begin{array}{l}\text { Zhao et al., } \\
2013\end{array}$ \\
\hline Ptns2 & $\begin{array}{l}\text { Ap }{ }^{r} \text {; helper strain for } \\
\text { mobilizing miniTn7 into } \\
\text { P. aeruginosa strains by } \\
\text { mating }\end{array}$ & $\begin{array}{l}\text { Choi and } \\
\text { Schweizer, } \\
2006\end{array}$ \\
\hline pGEM:tef & pGEM::tef, $A p^{r}$ & This research \\
\hline
\end{tabular}

\section{Taxonomic Classification of Isolates, Gene Calling, and Annotation}

Taxonomic classification of isolates was done by sequencing the genome of each isolate. DNA was purified using Exgene extraction kit (GeneAll, Korea) and prepared for sequencing using Nextera DNA sample preparation kit FC-131-1024 (Illumina, USA). De novo sequencing was performed on an Illumina MiSeq. Sequence data was quality trimmed using Trimmomatic (Bolger et al., 2014) and assembled using ABySS v. 1.5.2 (Simpson et al., 2009). The genomes are available on NCBI (BioSample: SAMN03295272, SAMN03352191, SAMN03352192). Phylogenetic classification of isolates was determined by concatenation of 120 phylogenetically informative proteins as previously described (Parks et al., 2017). Shortly, the completeness and contamination of the selected genomes was estimated using CheckM (Parks et al., 2015). These genomes were then subjected to gene calling by Prodigal (Hyatt et al., 2010) and search for the 120 phylogenetic informative proteins which were then aligned, both search and aliment were done by HMMER v.3.1b2 (Eddy, 1998). Trees were inferred with FastTree v.2.1.7 under WAG+ GAMMA models and decorated, rooted and bootstrapped using 100 non-parametric bootstrap replicates by GenomeTreeTk (https://github.com/dparks1134/ GenomeTreeTk).

\section{Molecular Methods}

Total DNA was extracted from $0.25 \mathrm{~g}$ roots using soil GeneAll kit (Geneall, Korea, soil DNA production kit, 114150) according to the manufacturer's protocol. Genomic DNA was extracted using GeneAll kit according to the manufacturer's protocol (Geneall,
Korea, Genomic DNA purification kit, K0512), plasmids were purified with the QIAprep Spin Miniprep Kit (QIAGEN, Germany). All primers were obtained from Integrated DNA Technologies (IDT). For quantifying plant gene copy number by qPCR, we used known DNA concentration of a specific plasmid containing the target region coding for translation elongation factor 1 (tef); pGEM:tef. For this purpose PCR primers listed in Table 2 for the tef region were used to amplify a 150-bp PCR product from wheat DNA as a template. To confirm the specify of amplification, the PCR product was analyzed by gel electrophoresis, and cloned into pGEM vector using pGEM cloning kit according to the manual (pGEM-T Vector, Promega, WI, USA).

Construction of chromosomally GFP-expressing strains the vector pUCP18-miniTn7T2.1Gm- GFP (Zhao et al., 2013) was used to chromosomally insert GFP to strains: NT0124, NT0128, NT0133. The vector was introduced together with pTNS2 helper plasmid into Pseudomonas isolates (NT0124, NT0128, and NT0133) by transformation as described by Choi and Schweizer (2006). Briefly, overnight culture of each strain was grown in $\mathrm{LB}$ medium at $30^{\circ} \mathrm{C}$ with shaking $(225 \mathrm{rpm})$. The next day, culture was divided into four Eppendorf tubes and centrifuged at $16,000 \mathrm{~g}$ and room temperature for $2 \mathrm{~min}$. The supernatant was discarded and cell pellet was suspended in $300 \mathrm{mM}$ cold sterile sucrose. This step was repeated 4 times. The electrocompetent cells were transferred to electroporation cuvette and equal amounts (100 ng) of the vector and helper plasmid were added to the cells. After electroporation, the cells were place in $\mathrm{LB}$ medium and incubated with shaking at $30^{\circ} \mathrm{C}$ for $1 \mathrm{~h}$ for recovering. After recovering, the cells were plated on LB plates supplemented with $\mathrm{Gm}$ antibiotics. The colonies obtained were confirmed using PCR which targeted the GFP gene as well as using fluorescence microscope (Choi and Schweizer, 2006; Zhao et al., 2013; Marmont et al., 2017).

\section{Motility Experiments}

Swimming plates contained 1\% tryptone (Difco Laboratories, USA), $0.5 \% \mathrm{NaCl}$ (Merck, Germany), and 0.3\% agar (Difco Laboratories, USA). Bacteria were taken with a toothpick from colonies grown overnight on LB plates and inoculated onto swimming plates by stabbing the agar with the toothpick midway and incubated at $30^{\circ} \mathrm{C}$ for $24 \mathrm{~h}$. Total of 8 different plates were used to calculate swimming potential by measuring the diameter of the bacterial colony formed. Twitching plates contained $1 \%$ tryptone (Difco Laboratories, USA), $0.5 \%$ yeast extract, $1 \% \mathrm{NaCl}$ (Merck, Germany), and 1\% agar (Difco Laboratories, USA). Bacteria were taken from colonies grown overnight on LB plates and inoculated onto twitching plates by stabbing the agar with the toothpick all through the agar and inoculated at $30^{\circ} \mathrm{C}$ for $24 \mathrm{~h}$. Total of 10 replicates were used to calculate twitching potential by measuring diameter of bacterial spread at the bottom of the plate after removing the agar and dying the bacteria at the bottom using crystal violet 1\% (c0775, Sigma, USA).

\section{Static Biofilm Assay}

Overnight grown liquid cultures were diluted 1:100 in LB and $100 \mu \mathrm{L}$ was transferred to each well in polystyrene 96-well plate (Nunclon, 167008, Nunc Brand Products, Denmark) and 
TABLE 2 | List of primers used in this study and their source.

\begin{tabular}{lll}
\hline Plant tef_f & ACTGTGCAGTAGTACTTGGTG & $\begin{array}{l}\text { Ruppel et al., } \\
2006\end{array}$ \\
Plant tef_r & AAGCTAGGAGGTATTGACAAG & $\begin{array}{l}\text { Ruppel et al., } \\
2006\end{array}$ \\
GFP_RT_f & CACTGGAGTTGTCCCAATTC & $\begin{array}{l}\text { This research } \\
\text { This research }\end{array}$ \\
GFP_RT_r & GGCCATGGAACAGGTAGTT & Milling et al., \\
F311Ps_f & CTGGTCTGAGAGGATGATCAGT & 2005 \\
Ps-rev_r & TTAGCTCCACCTCGCGGC & Widmer et al., \\
& & 1998 \\
rpoB_4042-4062_R & GATGTTTTGTACATCTTGG & This research \\
rpoB_3159-3178_F & GACAAGTTYGARGACAAGAAG & This research \\
\hline
\end{tabular}

incubated at $30^{\circ} \mathrm{C}$ for $20-24 \mathrm{~h}$. To measure biofilm formation in each well, plates were cleared of planktonic bacteria by double washing with water, filled with $150 \mu \mathrm{L}$ aqueous solution of $1 \%$ crystal violet (c0775, Sigma, USA) and incubated at room temperature for $15 \mathrm{~min}$. Unbound crystal violet was washed with water and biofilm-bound was extracted with $200 \mu \mathrm{L}$ ethanol (AC615090010, Fisher Scientific, USA). Hundred Microliter of the extracted crystal violet was transferred into a new 96-well plate and assessed by measuring the $\mathrm{OD}$ at $600 \mathrm{~nm}$ using platereader (iMark microplate reader, Bio-RAD, USA). Total of 24 wells repeats were analyzed for each isolate and 16 for PAO1.

\section{Plant Growth and Bacterial Colonization}

Wheat seeds (T. turgidum cv. Negev, Hazera, Israel) or cucumber seeds (Cucumis sativus cv. Kfir, Zeraim Gedera, Israel) were sterilized as described above. The sterilized seeds were cultivated in sterile mix of sandy loam soil with perlite 9:1 (w/w), hydrated with half-strength Hoagland solution (Ofek et al., 2014). For soil inoculation, bacteria were grown in LB overnight, diluted 1:100 in LB and grown for additional $3 \mathrm{~h}$ and washed 3 times with saline, then inoculated at $10^{6}$ bacteria per gram soilperlite mixture. Plants were grown for 10-12 days. After the growth period, the roots were carefully removed from the pots and washed in sterile saline and soil adhering to the roots was removed by vortex. Excess saline was removed from roots by putting them briefly on sterile filter paper and roots were weighted and used for either DNA extraction and qPCR or visualizing the bacterial colonization by confocal laser scanning microscopy.

\section{Confocal Laser Scanning Microscopy (CLSM)}

Roots were stained with Hoechst 3334 (Nucblue, R37605, Thermo Fisher, USA) according to the manufacture protocol. Images were acquired using either OLYMPUS IX 81 (Olympus Corporation, Japan) inverted laser scanning confocal microscope (FLUOVIEW 500) equipped with a 405 and 488 laser lines and a $20 \times 0.7$ NA UPlanApo objective, or Leica SP8 laser scanning microscope (Leica, Wetzlar, Germany), equipped with a solid state lasers with 405 and $488 \mathrm{~nm}$ light and HC PL APO CS2 20x/0.75 objective (Leica, Germany) and Leica Application Suite $\mathrm{X}$ software (LASX, Leica, Germany).

\section{Real-Time PCR Quantification (qPCR) of Root Colonization}

Average of $0.25 \mathrm{~g}$ of cucumber or wheat roots was collected from three different plants grown in the same pot for DNA extraction, as described above. Minimum of eight different replicates (individual pots) of each plant were used for quantifying the abundance of colonized isolates in root samples. Bacterial abundance on roots was quantified by targeting GFP (labeled isolate) and normalizing it to the copy number of the plant tef gene (pGEM:tef contained the tef region, coding for translation elongation factor). In all samples, GFP target numbers were divided by the tef target number, as described by Ofek et al. (2011). The primers used for quantifying each gene are listed in Table 2. Each gene copy numbers were calculated by StepOne software v2.3 (Applied Biosystems, CA, USA) using known DNA concentration and the specific plasmid (Table 2) plus insert molecular weight, estimated from their lengths. All qPCR assays were conducted in polypropylene 96-well plates and were performed using a StepOne Plus real-time PCR system (Applied Biosystems, USA). Plasmids DNA concentration was measured using Qubit fluorometric quantification (Thermo, Fisher scientific, USA) and Qubit dsDNA BR assay kit (Thermo, Fisher scientific, USA ,Q32853). Eight fold dilution series of the plasmids pGEM:tef and pBT270 and pUCP18-miniTn7T2.1GmGFP were conducted from $10^{\wedge 9}$ copies per $1 \mathrm{ml}$ to $10^{\wedge 2}$ copies per $1 \mathrm{ml}$. The standards and each sample within each treatment were tested in triplicates. The slope of the standard curve, correlation coefficient, and amplification efficacy were calculated using StepOne software v2.3. Reaction conditions were as follows: each $20 \mu \mathrm{L}$ reaction contained: $10 \mu \mathrm{L}$ Absolute Fast SYBR Green Master Mix (AB-4385612, Thermo, Fisher scientific, USA), 0.6 $\mu \mathrm{L}$ of each primer $(100 \mu \mathrm{M}), 7.8 \mu \mathrm{l} \mathrm{H}_{2} \mathrm{O}$, and $1 \mu \mathrm{L}$ template DNA (diluted 1:10). PCR conditions were: $5 \mathrm{~min}$ at $95^{\circ} \mathrm{C}$, followed by 40 cycles of $95^{\circ} \mathrm{C}$ for $5 \mathrm{~s}, 60^{\circ} \mathrm{C}$ for $30 \mathrm{~s}$. Melting curve analysis of the PCR products was conducted following each assay to confirm that the fluorescence signal originated from specific PCR products.

\section{Statistical Analysis}

Statistical analysis was done using JMP 13 software (Sall et al., 2012). Normal distribution of data was evaluated using the Shapiro-Wilk test for determining the use of parametric ( $p$ $>0.05)$ or non-parametric $(p<0.05)$ tests. Isolates biofilm formation capabilities was evaluated by comparing $\mathrm{OD}_{600}$ values using unpaired $t$-test with $p=0.05$ as threshold for rejecting the null hypothesis. Differences in motility rates, both swimming and twitching, were determined by comparing the diameter of the bacterial colony formed using the non-parametric Wilcoxon test. Finally, values resulting from the qPCR analysis determining colonization of isolates between plant types was analyzed using two way analysis of variance (ANOVA, $p<0.005, F$ ratio $=8.6$ ). 


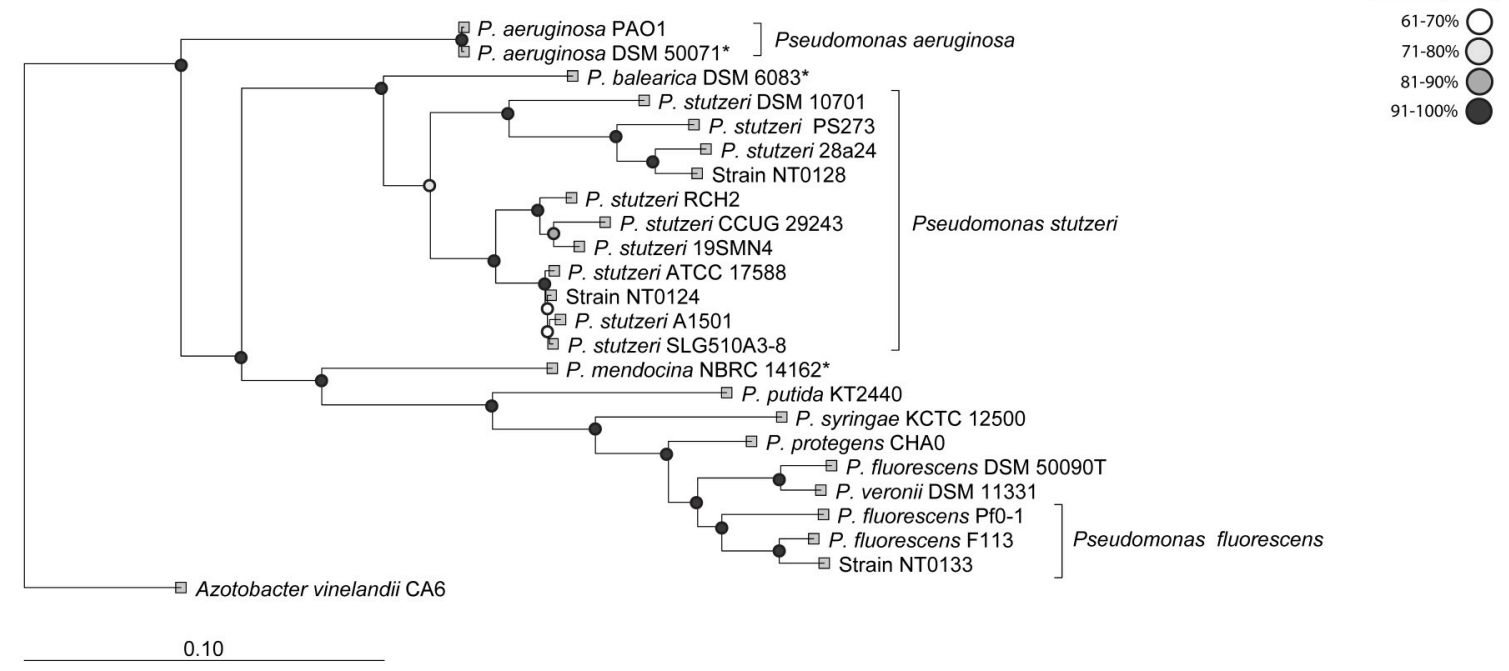

FIGURE 1 | Phylogenetic characterization of the three Pseudomonas isolates. The taxonomic annotation was done using 20 well-studied Pseudomonas strains as reference. The tree was inferred by the concatenation of 120 phylogenetically informative proteins (Parks et al., 2017). The names used are according to NCBI taxonomy and type strains are indicated by *.

\section{RESULTS}

\section{Isolation of Wheat Root Pseudomonas Populations}

We isolated approximately 70 putative Pseudomonas strains from wheat roots, on King's B medium. Their affiliation with the Pseudomonas genus was confirmed by PCR using two sets of Pseudomonas-specific primers: one targets the Pseudomonas 16S rRNA gene (Widmer et al., 1998; Milling et al., 2005) and another that targets Pseudomonas rpoB gene (Table 2). Of the 70 isolates, only 30 were positively identified by both Pseudomonas-specific primer sets. These isolates were clustered into four groups, based on morphology and Enterobacterial Repetitive Intergenic Consensus (ERIC) PCR patterns (De Bruijn, 1992). Converging evidence, based on ERIC PCR and $r p o B$ gene sequencing, suggested that most of the isolates were closely related to P. stutzeri. Three isolates, namely NT0124, NT0128, and NT0133, were selected as representatives of the three main wheat pseudomonas populations (one group had only one isolate, which did not survive in cultivation). The taxonomic inference of the three isolates was performed by the concatenation of 120 proteins previously found to be phylogenetic informative (Parks et al., 2017). Results showed that each of the isolates was phylogenetically distinct (Figure 1). Two isolates (NT0124, NT0128) were annotated as two strains of $P$. stutzeri and one (NT0133) as a strain of $P$. fluorescens. To gain more information regarding differences between the isolates we characterized several traits known to be important for plant root colonization. Comparing unique and shared orthologs predicted open reading frames (ORFs) showed that each of the isolates share between 53.8 and $65.1 \%$ ORF, with only $11.2-34.6 \%$ unique ORF (Figure S1).

\section{Motility and Biofilm Formation}

Motility has an important role in biofilm formation and host colonization (O'toole and Kolter, 1998; Mattick, 2002). The three isolates were tested for two types of motility: swimming (involves flagella) and twitching (mediated by type IV pili) and expansion zone was used to measure both types (Mattick, 2002). $P$. aeruginosa PA01 served for comparison and as a positive control for motility and biofilm formation, as this strain is often used as model bacteria for these traits (Costerton et al., 1999; Mattick, 2002; Sriramulu et al., 2005). Both isolates NT0124 and NT0128 surpassed isolate NT0133 motility performances (Figure 2A). Twitching motility of isolates NT0124 and NT0128 was found to be at a similar level to that of PAO1, at a diameter of around $6-8 \mathrm{~mm}$. Isolate NT0133, on the other hand, had impaired twitching motility activities compared to NT0124 and NT0128 $(p<0.0001)$ and did not show twitching ability. Strain NT0124 was found to be the most superior swimmer, 1.5 times faster than PAO1 $(p<0.0002)$. NT0133 was significantly less motile than NT0124 $(p<0.0001)$ and NT0128 $(p<0.0002)$ (Figure 2A).

The three selected isolates were examined for biofilm formation ability by the commonly used crystal violet assay (O’Toole, 2011; Coffey and Anderson, 2014). All three strains formed biofilm to some degree (Figure 2B). However, isolates NT0124 and NT0128, both showed hyper-biofilm phenotype, in contrast to isolate NT0133 which formed three times less biofilm under the same conditions. Isolate NT0124 biofilm level was similar to that of P. aeruginosa PA01, and NT0128 biofilm levels were even higher ( $p$ value for NT0133 and NT0124 $p<0.0001$, $\mathrm{t}$ Ratio $=-7.3$, for NT0133 and NT0128 $p<0.0001$, $\mathrm{t}$ Ratio $=$ -9.2 , for PAO1 and NT0128 $p<0.001$, $\mathrm{t}$ Ratio $=-2.4$ and for PAO1 and NT0133 $p<0.0001$, t Ratio $=6.1$ ). 


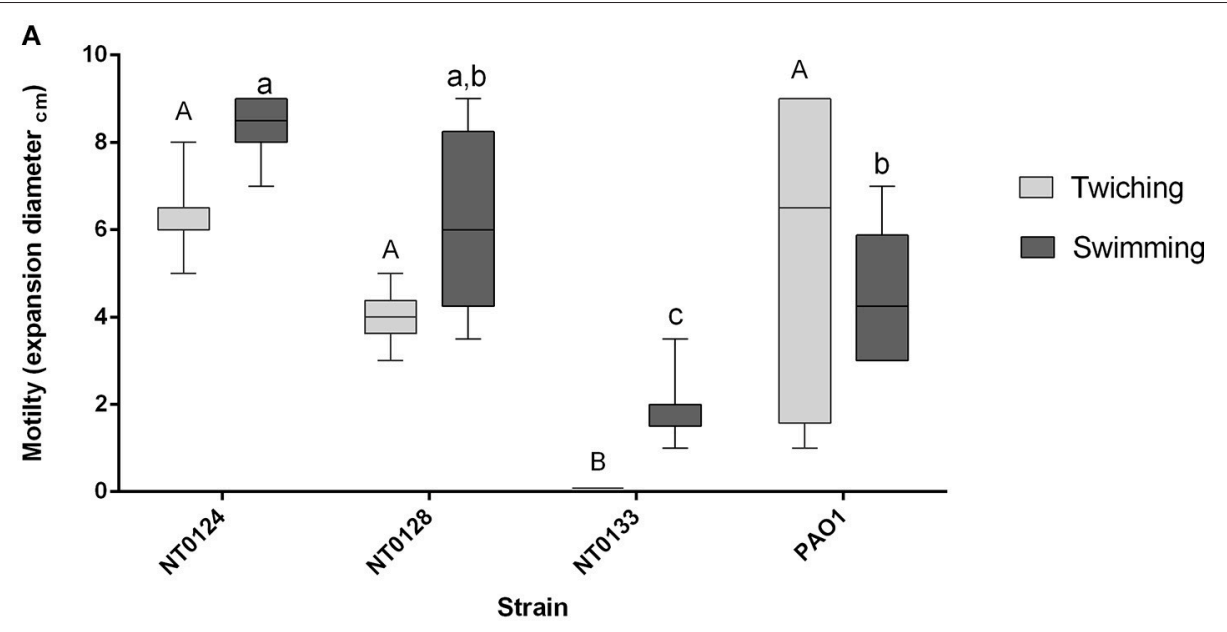

B

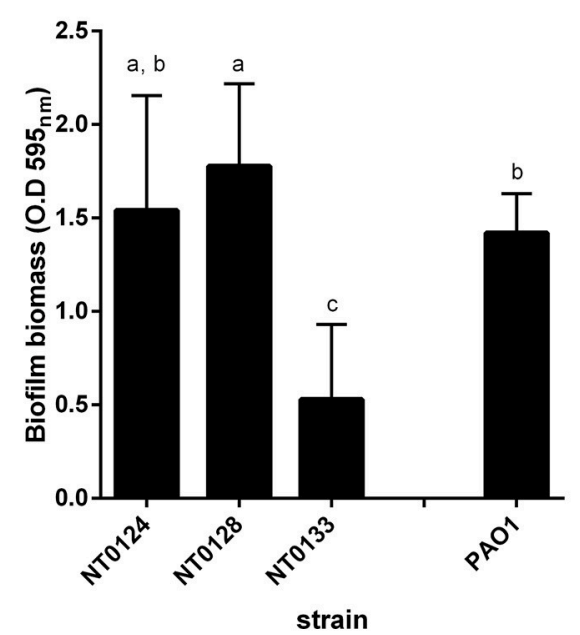

FIGURE 2 | Motility and biofilm formation of isolates NT0124, NT0128, NT0133, and the reference bacteria PAO1. (A) Motility levels of the isolates, measured as colony expansion zone diameter formed after $24 \mathrm{~h}$ of growth on agar plates [in light gray: twitching motility $(n=8)$ and in dark gray: swimming motility $(n=10)$ ]. The expansion zones in each motility type were significantly different between each of the strains levels not connected by the same letters are significantly different $\mathrm{A}$-B and a-c ( $<$ <.0002). Isolate NT0133 did not show twitching ability. Error bars indicate standard deviation and bar line represents average. (B) Biofilm biomass formed by the isolates. Error bars indicate standard deviation. Isolates NT0124, NT0128, and PAO1 were significantly different than NT0133 [ $p$ <.0001, $(n>16)$ levels not connected by the same letters are significantly different a-c].

\section{Pseudomonas Isolates Patterns of Root Colonization}

In order to successfully utilize bacteria in the root, it is important to understand why one species is found in one plant and not in another. We hypothesized that the wheat-derived isolates will better colonize wheat roots compared to cucumber. In addition, we hypothesized that an isolate with higher biofilm formation ability will also be a better root colonizer. We examined and followed the ability of the three isolates to colonize wheat and cucumber roots by two methods: quantitatively, using qPCR analysis (Figure 3) and qualitatively on root topography, using CLSM (Figure 4).

Soil inoculated with the three GFP labeled strains, as described in the methods section, was used to grow either wheat or cucumber seedlings. The roots of 10-12 days old seedlings were used for assessing bacterial colonization. Root colonization was quantified using qPCR targeting unique GFP gene sequences in each isolate and primers that target a plant gene (tef) representing plant cells number. qPCR results (Figure 3) showed that the abundance of all three isolates, normalized to tef copy number, was significantly affected by the plant type (Two way ANOVA $p<0.005, \mathrm{~F}$ ratio $=8.6)$. All three isolates colonized wheat, on average at a level of 34 bacterial cells per root cell, while isolates NT0124 and NT0128 showed a slightly higher GFP copy number per root cell. Normalized GFP copy number on cucumber root was at least 10 times lower than wheat root, suggesting preferential colonization of isolates. Isolates NT0124 and NT0128 seem to be the best wheat root colonizers. 


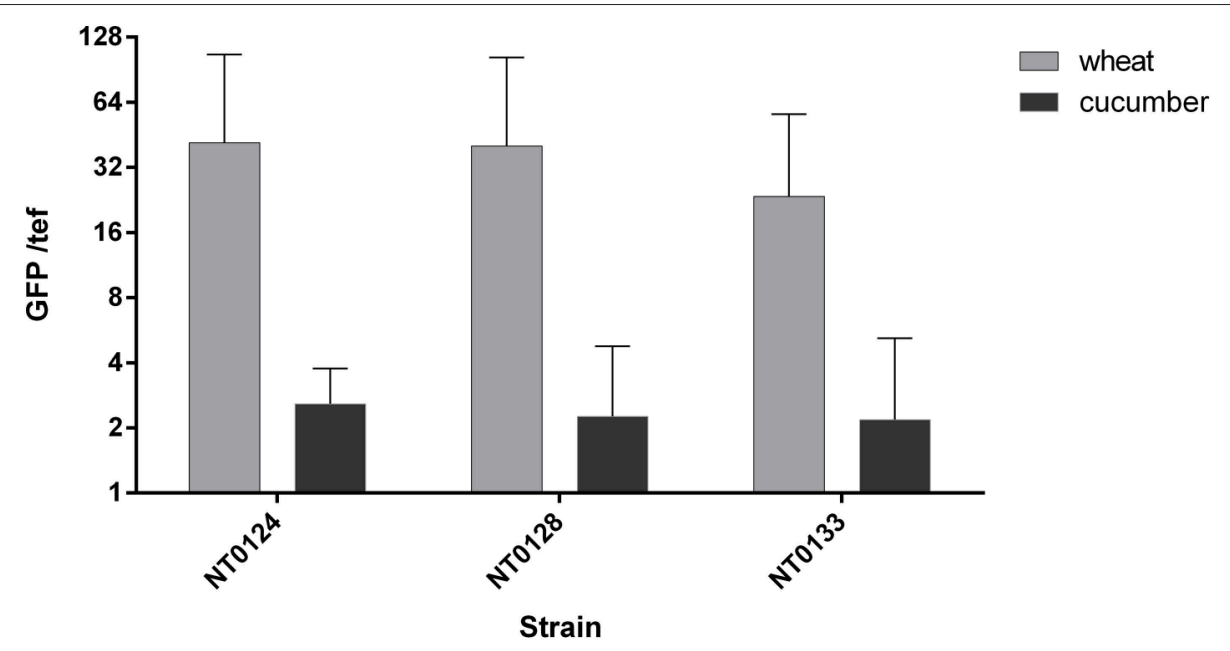

FIGURE 3 | Wheat and cucumber root colonization by the isolates. Real-time qPCR analysis was conducted by quantifying GFP copy numbers and normalizing by plant tef copies. Error bars indicate standard deviation $(n>8)$. Two way ANOVA analysis revealed significant difference between abundance of all isolates as affected by the plant type $(p<0.005$, F ratio $=8.6)$.

Colonization of the GFP labeled strains was analyzed by using CLSM (Figure 4). CLSM sections of each isolate in both plants were taken from the same root starting from the tip toward the upper $1.5 \mathrm{~cm}$. CLSM images further demonstrated wheat over cucumber colonization preference, supporting the qPCR results. Additionally, CLSM showed that each of the isolates had a different spatial distribution on wheat root. Isolate NT0128 did not show any preference toward a specific niche of wheat roots (Figures 4A.5-A.8), exhibiting a root wide colonization distribution. In contrast, NT0124 and NT0133, which were better wheat root colonizers, showed preference in specific zones. NT0124 colonized preferentially the zones closest to the roots tip (Figures 4A.1-A.4). Interestingly, this isolate also showed high preference toward root hairs and formed massive biofilms (Figure S2). Isolate NT0133, on the other hand, showed colonization preference toward the zone distant from the root tip (1-1.5 cm from the root tip) (Figures 4A.9-A.12). However, all three isolates were barely found along cucumber roots at the studied zones (Figures 4A.9-A.12,B.1-B.4).

\section{DISCUSSION}

Theories in ecology suggest that forces such as availability of resources and competition will restrict the number of species sharing the same niche (Hardin, 1960; Leibold and McPeek, 2006; Ghoul and Mitri, 2016). The root environment has high diversity of bacteria; many of them compete for space and nutrients obtained from the soil, but more so from the root itself. In addition, root deposits are known to differ by plant species and along the root (Badri and Vivanco, 2009; Berendsen et al., 2012; Bulgarelli et al., 2012). Several studies suggest that plant host can influence the composition and activity of its root microbiome. For example, cereals roots were shown to often be rich in members of the genus Pseudomonas (Ofek et al., 2014; Rascovan et al., 2016). However, little is known on the spatial distribution and preference of root species coexisting in the same niche.

Three dominant Pseudomonas strains were isolated from wheat roots, to examine their pattern of colonization and specifically their niche preference. Two isolates (NT0124, NT0128) were closely related to the P. stutzeri group, members of which were previously shown to colonize plant roots and have great importance in the nitrogen requirement of plants and in degradation of aromatic compounds (Dekkers et al., 1998; Lugtenberg and Dekkers, 1999; Rediers et al., 2009; Silby et al., 2011). The third isolate NT0133, was related to P. fluorescens, which often serves as a model organism for the description of root colonization processes (Rivilla et al., 2013; Ramos et al., 2015). Members of $P$. fluorescens group are often found on plant roots and in soils and some strains of this group are known for their abilities to protect plants from pathogens (Silby et al., 2011) and promote wheat growth (Capper and Higgins, 1993; Weller, 2007). All three isolates preferentially colonized wheat roots over those of cucumber, suggesting host specificity. Furthermore, similar experiments showed preference to other cereals (barley and maize) in comparison to soybeans (data not shown). Our results show that the three isolates differ in motility and biofilm formation traits, both considered important in root colonization. Surprisingly, those traits appear not to predict which isolate will succeed in colonizing plants roots. It has been shown here, and in other studies (Lugtenberg and Dekkers, 1999; Lugtenberg et al., 2001; Velázquez-Sepúlveda et al., 2012; Ofek-Lalzar et al., 2014; Rascovan et al., 2016), that the plant host appears to determine which bacterial species may succeed in its colonization. In the current study, we suggest that the plant host may also have a role in shaping the particular location of colonization. Our findings strongly suggest that the exact localization of colonization on the roots can vary, even between related bacterial species. One would assume that three related organisms will compete for nutrients and space and thus not inhabit the same niche (Hardin, 


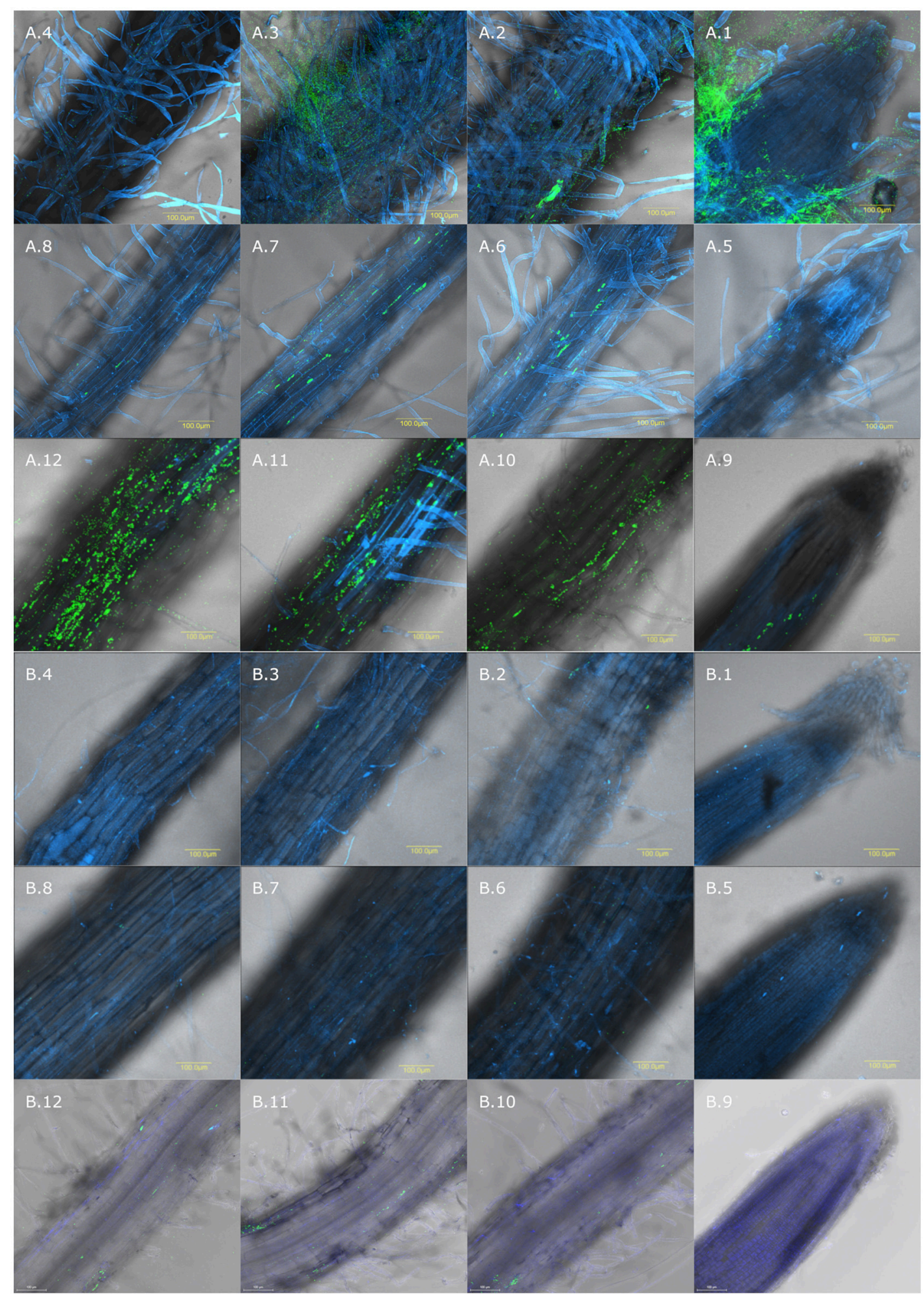

FIGURE 4 | Spatial distribution of colonization on wheat and cucumber roots evaluated by CLSM. Wheat and cucumber roots were sampled after 10-12 days of growth in soil inoculated with GFP labeled isolates. Root is labeled in blue using Hoechst dye and GFP labeled bacteria are shown in green. Wheat roots inoculated with: (A.1-A.4) isolate NT0124; (A.5-A.8) NT0128; (A.9-A.12) NT0133; Cucumber roots inoculated with: (B.1-B.4) NT0124, (B.5-B.8) NT0128; (B.9-B.12) NT0133, (1) In all the panels; (1) root tip, (2) $0.5 \mathrm{~cm}$ from the root tip (3) $1 \mathrm{~cm}$ from root tip and (4) $1.5 \mathrm{~cm}$ from the root tip. The different sections of each isolate in both plants, were taken from the same root, starting from the tip toward the upper $1.5 \mathrm{~cm}$. The pictures represent multiple roots from at least two different individual experiments. 
1960; Hibbing et al., 2010; Ghoul and Mitri, 2016). Indeed, these different characteristics in motility and biofilm formation and colonization traits may have a role in shaping the spatial distribution and coexistence of these related isolates on the roots. The preferred localization of a bacterial species along the root may indicate differences in available resources. It is assumed that different root deposits may be abundant at the various root zones, e.g., near the root tip, near the zone of maturation, which has numerous root hairs, or in microcolonies co-colonizing with other microorganisms (Walker et al., 2003; Badri and Vivanco, 2009; Dennis et al., 2010; Sasse et al., 2017). In addition to the metabolic capabilities, other bacterial traits might reason the distinct spatial distribution of the strains. The highly motile isolate NT0124 was found to preferentially colonize the zone near the tip. Succeeding at this location may be explained by this strains ability to "chase" the tip as the root elongates. As plant root grows, the root tip is pushed forward, and thus motile bacteria will have an advantage in consistently colonizing the root tip, a major zone of exudate secretion (Badri and Vivanco, 2009). NT0128 showed similar abundance to NT0124 on wheat roots, however, without preference on zone of colonization. The difference between the two isolates could result from variety of traits. For example, the possibility that NT0128 is less selective in resource utilization, which may expand its colonization possibilities. Such hypothesis is supported by difference in their genomes; the two isolates share only $707 \mathrm{ORFs}$ out of total of 4071 of NT0124 and 4202 of NT0128 (Figure S1) and although both isolates were identified as $P$. stutzeri they belong to two different phylogenetic clades (Figure 1). In addition, on the plate assay NT0124 motility was slightly faster than NT0128. In the root environment this phenomenon could be more pronounced, giving NT0124 an advantage in continuously moving niche such as the root tip. Lastly, isolate NT0133 showed high competence and preference in colonizing the zone distant from the wheat root tip, suggesting adaptation to this niche. Ultimately, the data presented here demonstrates that understanding bacterial motility may be important in predicting the niche preference of a specific strain.

The importance of flagella-dependent motility to root colonization is still under debate. Some studies reported that non-motile mutants of Pseudomonas are not impaired in root colonization of wheat and soybean (Howie et al., 1987; Scher et al., 1988; Lugtenberg et al., 2001), while others showed that some non-motile mutants were severely impaired in colonization of potato and tomato root (De Weger et al., 1987; Lugtenberg et al., 2001). This discrepancy in results might be explained now by authors disregard to micro-niche preferences of the Pseudomonas strains they used. Motility is also required for the early stages of biofilm formation and for

\section{REFERENCES}

Badri, D. V., and Vivanco, J. M. (2009). Regulation and function of root exudates. Plant Cell Environ. 32, 666-681. doi: 10.1111/j.1365-3040.2009.01926.x

Berendsen, R. L., Pieterse, C. M., and Bakker, P. A. (2012). The rhizosphere microbiome and plant health. Trends Plant Sci. 17, 478-486. doi: 10.1016/j.tplants.2012.04.001 surface attachment. In the biofilm state the bacteria are better protected and this trait was shown to be especially important for adaptation to living on roots (Walker et al., 2004). Our strains successfully form biofilm; NT0124 and NT0128 biofilm formation on polystyrene surface was at levels equivalent to that of the commonly used biofilm model PAO1 and indeed formed massive biofilm on wheat roots. While isolate NT0133 form less biofilm on abiotic polystyrene surface, this did not affect its ability to adhere and colonize the non-moving parts of wheat roots. This suggests that successfull root colonization is not influenced solely by motility and biofilm formation competence.

Our results demonstrate that different areas along roots can favor different species. Even related species can have significant variation in their spatial colonization patterns, governed by both niche and bacterial characteristics. These findings can help our understanding of plant-bacteria interaction and pave the road for studies that will elucidate the mechanisms by which bacteria and plants select each other. This understanding may be of importance in future attempts to interfere with root microbiomes, construct and design effective synthetic communities.

\section{AUTHOR CONTRIBUTIONS}

NT, YH, and DM designed the experiments. NT performed the experiments. SF analyzed and the genomes sequences. All authors jointly wrote the manuscript.

\section{ACKNOWLEDGMENTS}

We would like to thank Eduard Belausov for his assistance in confocal laser-scanning microscopy. We thank Maya Lalzar for her comments and helpful criticism. We thank Joe Harrison from Calgary University, Canada for providing the plasmids for GFP construction.

\section{SUPPLEMENTARY MATERIAL}

The Supplementary Material for this article can be found online at: https://www.frontiersin.org/articles/10.3389/fmicb. 2018.03263/full\#supplementary-material

Figure S1 | Venn diagram depicting numbers of unique and shared orthologs predicted open reading frames (ORFs). Orthology was determined using ProteinOrtho software. The number of ORFs corresponding to the number of orthologs is in parenthesis.

Figure S2 | Enlargement of zone showed in picture A.1 $(0.5 \mathrm{~cm}$ from wheat root tip). Wheat roots were sampled after 10-12 days of growth in soil and soil was inoculated with isolate NT0124 which formed massive biofilm on wheat hairs.

Bolger, A. M., Lohse, M., and Usadel, B. (2014). Trimmomatic: a flexible trimmer for Illumina sequence data. Bioinformatics 30, 2114-2120. doi: 10.1093/bioinformatics/btu170

Bulgarelli, D., Rott, M., Schlaeppi, K., van Themaat, E. V. L., Ahmadinejad, N., Assenza, F., et al. (2012). Revealing structure and assembly cues for Arabidopsis root-inhabiting bacterial microbiota. Nature 488, 91-95. doi: 10.1038/nature11336 
Capper, A., and Higgins, K. (1993). Application of Pseudomonas fluorescens isolates to wheat as potential biological control agents against take-all. Plant Pathol. 42, 560-567. doi: 10.1111/j.1365-3059.1993.tb01536.x

Choi, K.-H., and Schweizer, H. P. (2006). mini-Tn7 insertion in bacteria with single attTn7 sites: example Pseudomonas aeruginosa. Nat. Protoc. 1, 153-161. doi: $10.1038 /$ nprot.2006.24

Coffey, B. M., and Anderson, G. G. (2014). Biofilm formation in the 96-well microtiter plate. Methods Mol. Biol. 1149, 631-641. doi: 10.1007/978-1-4939-0473-0_48

Costerton, J. W., Stewart, P. S., and Greenberg, E. P. (1999). Bacterial biofilms: a common cause of persistent infections. Science 284, 1318-1322. doi: $10.1126 /$ science.284.5418.1318

De Bruijn, F. J. (1992). Use of repetitive (repetitive extragenic palindromic and enterobacterial repetitive intergeneric consensus) sequences and the polymerase chain reaction to fingerprint the genomes of Rhizobium meliloti isolates and other soil bacteria. Appl. Environ. Microbiol. 58, 2180-2187.

De Weger, L. A., Van der Vlugt, C., Wijfjes, A., Bakker, P., Schippers, B., and Lugtenberg, B. (1987). Flagella of a plant-growth-stimulating Pseudomonas fluorescens strain are required for colonization of potato roots. J. Bacteriol. 169, 2769-2773. doi: 10.1128/jb.169.6.2769-2773.1987

Dekkers, L. C., Bloemendaal, C. J. P., de Weger, L. A., Wijffelman, C. A., Spaink, H. P., and Lugtenberg, B. J. (1998). A two-component system plays an important role in the root-colonizing ability of Pseudomonas fluorescens strain WCS365. Mol. Plant Microbe Interact. 11, 45-56. doi: 10.1094/MPMI.1998.11.1.45

Dennis, P. G., Miller, A. J., and Hirsch, P. R. (2010). Are root exudates more important than other sources of rhizodeposits in structuring rhizosphere bacterial communities? FEMS Microbiol. Ecol. 72, 313-327. doi: 10.1111/j.1574-6941.2010.00860.x

Eddy, S. R. (1998). Profile hidden Markov models. Bioinformatics 14, 755-763. doi: 10.1093/bioinformatics/14.9.755

Gause, G. (1936). The struggle for existence. Soil Sci. 41:159. doi: 10.1097/00010694-193602000-00018

Ghoul, M., and Mitri, S. (2016). The ecology and evolution of microbial competition. Trends Microbiol. 24, 833-845. doi: 10.1016/j.tim.2016.06.011

Hardin, G. (1960). The competitive exclusion principle. Science 131, 1292-1297.

Harshey, R. M. (2003). Bacterial motility on a surface: many ways to a common goal. Ann. Rev. Microbiol. 57, 249-273. doi: 10.1146/annurev.micro.57.030502.091014

Hibbing, M. E., Fuqua, C., Parsek, M. R., and Peterson, S. B. (2010). Bacterial competition: surviving and thriving in the microbial jungle. Nat. Rev. Microbiol. 8:15. doi: $10.1038 /$ nrmicro2259

Holloway, B. (1955). Genetic recombination in Pseudomonas aeruginosa. Microbiology 13, 572-581.

Howie, W., Cook, R., and Weller, D. (1987). Effects of soil matric potential and cell motility on wheat root colonization by fluorescent pseudomonads suppressive to take-all. Phytopathology 77, 286-292. doi: 10.1094/Phyto-77-286

Hyatt, D., Chen, G.-L., LoCascio, P. F., Land, M. L., Larimer, F. W., and Hauser, L. J. (2010). Prodigal: prokaryotic gene recognition and translation initiation site identification. BMC Bioinformatics 11:119. doi: 10.1186/1471-2105-11-119

Jones, D. L., Hodge, A., and Kuzyakov, Y. (2004). Plant and mycorrhizal regulation of rhizodeposition. New Phytol. 163, 459-480. doi: $10.1111 / j .1469-8137.2004 .01130 . x$

King, E. O., Ward, M. K., and Raney, D. E. (1954). Two simple media for the demonstration of pyocyanin and fluorescin. Transl. Res. 44, 301-307.

Kravchenko, L., Azarova, T., Leonova-Erko, E., Shaposhnikov, A., Makarova, N., and Tikhonovich, I. (2003). Root exudates of tomato plants and their effect on the growth and antifungal activity of Pseudomonas strains. Microbiology 72, 37-41. doi: 10.1023/A:1022269821379

Lareen, A., Burton, F., and Schäfer, P. (2016). Plant root-microbe communication in shaping root microbiomes. Plant Mol. Biol. 90, 575-587. doi: 10.1007/s11103-015-0417-8

Leibold, M. A., and McPeek, M. A. (2006). Coexistence of the niche and neutral perspectives in community ecology. Ecology 87, 1399-1410. doi: 10.1890/00129658(2006)87[1399:COTNAN]2.0.CO;2

Lugtenberg, B., and Kamilova, F. (2009). Plant-growthpromoting rhizobacteria. Annu. Rev. Microbiol. 63, 541-556. doi: 10.1146/annurev.micro.62.081307.162918
Lugtenberg, B. J., Dekkers, L., and Bloemberg, G. V. (2001). Molecular determinants of rhizosphere colonization by Pseudomonas. Annu. Rev. Phytopathol. 39, 461-490. doi: 10.1146/annurev.phyto.39.1.461

Lugtenberg, B. J., and Dekkers, L. C. (1999). What makes Pseudomonas bacteria rhizosphere competent? Environ. Microbiol. 1, 9-13. doi: 10.1046/j.1462-2920.1999.00005.x

MacArthur, R., and Levins, R. (1967). The limiting similarity, convergence, and divergence of coexisting species. Am. Nat. 101, 377-385. doi: 10.1086/282505

Marmont, L. S., Rich, J. D., Whitney, J. C., Whitfield, G. B., Almblad, H., Robinson, H., et al. (2017). Oligomeric lipoprotein PelC guides Pel polysaccharide export across the outer membrane of Pseudomonas aeruginosa. Proc. Nat. Acad. Sci. U.S.A. 114, 2892-2897. doi: 10.1073/pnas.1613606114

Mattick, J. S. (2002). Type IV pili and twitching motility. Ann. Rev. Microbiol. 56, 289-314. doi: 10.1146/annurev.micro.56.012302.160938

Milling, A., Smalla, K., Maidl, F. X., Schloter, M., and Munch, J. C. (2005). Effects of transgenic potatoes with an altered starch composition on the diversity of soil and rhizosphere bacteria and fungi. Plant Soil 266, 23-39. doi: 10.1007/s11104-005-4906-4

Ofek, M., Hadar, Y., and Minz, D. (2011). Colonization of cucumber seeds by bacteria during germination. Environ. Microbiol. 13, 2794-2807. doi: $10.1111 / j .1462-2920.2011 .02551 . x$

Ofek, M., Voronov-Goldman, M., Hadar, Y., and Minz, D. (2014). Host signature effect on plant root-associated microbiomes revealed through analyses of resident vs. active communities. Environ. Microbiol. 16, 2157-2167. doi: 10.1111/1462-2920.12228

Ofek-Lalzar, M., Sela, N., Goldman-Voronov, M., Green, S. J., Hadar, Y., and Minz, D. (2014). Niche and host-associated functional signatures of the root surface microbiome. Nat. Commun. 5:4950. doi: 10.1038/ncomms5950

O’Toole, G. A. (2011). Microtiter dish biofilm formation assay. J. Vis. Exp. e2437. doi: $10.3791 / 2437$

O'toole, G. A., and Kolter, R. (1998). Flagellar and twitching motility are necessary for Pseudomonas aeruginosa biofilm development. Mol. Microbiol. 30, 295-304. doi: 10.1046/j.1365-2958.1998.01062.x

Parks, D. H., Imelfort, M., Skennerton, C. T., Hugenholtz, P., and Tyson, G. W. (2015). CheckM: assessing the quality of microbial genomes recovered from isolates, single cells, and metagenomes. Genome Res. 25, 1043-1055. doi: $10.1101 /$ gr.186072.114

Parks, D. H., Rinke, C., Chuvochina, M., Chaumeil, P.-A., Woodcroft, B. J., Evans, P. N., et al. (2017). Recovery of nearly 8,000 metagenome-assembled genomes substantially expands the tree of life. Nat. Microbiol. 2:1533. doi: 10.1038/s41564-017-0012-7

Philippot, L., Raaijmakers, J. M., Lemanceau, P., and Van Der Putten, W. H. (2013). Going back to the roots: the microbial ecology of the rhizosphere. Nat. Rev. Microbiol. 11:789. doi: 10.1038/nrmicro3109

Poole, P. (2017). Shining a light on the dark world of plant rootmicrobe interactions. Proc. Nat. Acad. Sci. U.S.A. 114, 4281-4283. doi: 10.1073/pnas.1703800114

Rainey, P. B. (1999). Adaptation of Pseudomonas fluorescens to the plant rhizosphere. Environ. Microbiol. 1, 243-257. doi: 10.1046/j.1462-2920.1999.00040.x

Ramey, B. E., Koutsoudis, M., von Bodman, S. B., and Fuqua, C. (2004). Biofilm formation in plant-microbe associations. Curr. Opin. Microbiol. 7, 602-609. doi: 10.1016/j.mib.2004.10.014

Ramos, J. L., Goldberg, J. B., and Filloux, A. (ed). (2015). Pseudomonas, Vol. 7, New Aspects of Pseudomonas Biology. Dordrecht: Springer.

Rascovan, N., Carbonetto, B., Perrig, D., Díaz, M., Canciani, W., Abalo, M., et al. (2016). Integrated analysis of root microbiomes of soybean and wheat from agricultural fields. Sci. Rep. 6:28084. doi: 10.1038/srep28084

Rediers, H., Vanderleyden, J., and De Mot, R. (2009). Nitrate respiration in Pseudomonas stutzeri A15 and its involvement in rice and wheat root colonization. Microbiol. Res. 164, 461-468. doi: 10.1016/j.micres.2007.03.003

Rivilla, R., Martínez-Granero, F., and Martín, M. (2013). Motility, biofilm formation and rhizosphere colonization by Pseudomonas fluorescens F113. Mol. Microb. Ecol. Rhizosphere 1, 723-732. doi: 10.1002/9781118297674.ch68

Rodríguez-Navarro, D. N., Dardanelli, M. S., and Ruíz-Saínz, J. E. (2007). Attachment of bacteria to the roots of higher plants. FEMS Microbiol. Lett. 272, 127-136. doi: 10.1111/j.1574-6968.2007.00761.x 
Ruppel, S., Rühlmann, J., and Merbach, W. (2006). Quantification and localization of bacteria in plant tissues using quantitative real-time PCR and online emission fingerprinting. Plant Soil 286, 21-35. doi: 10.1007/s11104-0069023-5

Sall, J., Lehman, A., Stephens, M. L., and Creighton, L. (2012). JMP Start Statistics: A Guide to Statistics and Data Analysis Using JMP. Cary, NC: SAS Institute.

Santoyo, G., Orozco-Mosqueda, M. d. C., and Govindappa, M. (2012). Mechanisms of biocontrol and plant growth-promoting activity in soil bacterial species of Bacillus and Pseudomonas: a review. Biocontrol Sci. Technol. 22, 855-872. doi: 10.1080/09583157.2012.694413

Sasse, J., Martinoia, E., and Northen, T. (2017). Feed your friends: do plant exudates shape the root microbiome? Trends Plant Sci. 23, P25-P41. doi: 10.1016/j.tplants.2017.09.003

Scher, F., Kloepper, J., Singleton, C., Zaleska, I., and Laliberte, M. (1988), Colonization of soybean roots by Pseudomonas and Serratia species: relationship to bacterial motility, chemotaxis, and generation time. Phytopathology 78, 1055-1059. doi: 10.1094/Phyto-78-1055

Silby, M. W., Winstanley, C., Godfrey, S. A., Levy, S. B., and Jackson, R. W. (2011). Pseudomonas genomes: diverse and adaptable. FEMS Microbiol. Rev. 35, 652-680. doi: 10.1111/j.1574-6976.2011.00269.x

Simpson, J. T., Wong, K., Jackman, S. D., Schein, J. E., Jones, S. J., and Birol, I. (2009). ABySS: a parallel assembler for short read sequence data. Genome Res. 19, 1117-1123. doi: 10.1101/gr.089532.108

Sriramulu, D. D., Lünsdorf, H., Lam, J. S., and Römling, U. (2005). Microcolony formation: a novel biofilm model of Pseudomonas aeruginosa for the cystic fibrosis lung. J. Med. Microbiol. 54, 667-676. doi: 10.1099/jmm.0.45969-0

Uroz, S., Buée, M., Murat, C., Frey-Klett, P., and Martin, F. (2010). Pyrosequencing reveals a contrasted bacterial diversity between oak rhizosphere and surrounding soil. Environ. Microbiol. Rep. 2, 281-288. doi: 10.1111/j.1758-2229.2009.00117.x

Velázquez-Sepúlveda, I., Orozco-Mosqueda, M., Prieto-Barajas, C., and Santoyo, G. (2012). Bacterial diversity associated with the rhizosphere of wheat plants
(Triticum aestivum): toward a metagenomic analysis. Phyton, Int. J. Exp. Bot. 81, 81-87.

Walker, B., Holling, C., Carpenter, S., and Kinzig, A. (2004). Ecology and society, resilience, adaptability and transformability in social-ecological systems. Ecol. Soc. 9:5. doi: 10.5751/ES-00650-090205

Walker, T. S., Bais, H. P., Grotewold, E., and Vivanco, J. M. (2003). Root exudation and rhizosphere biology. Plant Physiol. 132, 44-51. doi: 10.1104/pp.102.019661

Weller, D. M. (1988). Biological control of soilborne plant pathogens in the rhizosphere with bacteria. Annu. Rev. Phytopathol. 26, 379-407. doi: 10.1146/annurev.py.26.090188.002115

Weller, D. M. (2007). Pseudomonas biocontrol agents of soilborne pathogens: looking back over 30 years. Phytopathology 97, 250-256. doi: 10.1094/PHYTO-97-2-0250

Widmer, F., Seidler, R. J., Gillevet, P. M., Watrud, L. S., and Di Giovanni, G. D. (1998). A highly selective PCR protocol for detecting 16S rRNA genes of the genus Pseudomonas (sensu stricto) in environmental samples. Appl. Environ. Microbiol. 64, 2545-2553.

Zhao, K., Tseng, B. S., Beckerman, B., Jin, F., Gibiansky, M. L., Harrison, J. J., et al. (2013). Psl trails guide exploration and microcolony formation in Pseudomonas aeruginosa biofilms. Nature 497:388. doi: 10.1038/nature12155

Conflict of Interest Statement: The authors declare that the research was conducted in the absence of any commercial or financial relationships that could be construed as a potential conflict of interest.

Copyright (c) 2019 Tovi, Frenk, Hadar and Minz. This is an open-access article distributed under the terms of the Creative Commons Attribution License (CC BY). The use, distribution or reproduction in other forums is permitted, provided the original author(s) and the copyright owner(s) are credited and that the original publication in this journal is cited, in accordance with accepted academic practice. No use, distribution or reproduction is permitted which does not comply with these terms. 